\title{
A DEMOCRACIA GLOBAL DECORRENTE DA TRANSNACIONALIZAÇÃO DO ESTADO MODERNO: A (IM)POSSIBILIDADE DA CRIAÇÃO DE SISTEMAS DEMOCRÁTICOS INTERNACIONAIS SEGUNDO ROBERT DAHL, DAVID HELD E ANNE PETERS
}

\section{Alvaro de Olivelra Azevedo Neto}

Bacharel em Direito pela Universidade Católica de Pernambuco (2003), mestre em Ciência Política, com concentração na linha de Políticas Internacionais de Integração pela Universidade Federal de Pernambuco (2005), doutor em Direito, com concentração na linha de Neoconstitucionalismo, pela Universidade Federal de Pernambuco (2010). Atualmente é Coordenador Acadêmico do Curso de Direito da Faculdade Boa Viagem, em Recife, Pernambuco; professor do Centro Universitário do Vale do Ipojuca, em Caruaru Pernambuco; e do Centro Universitário Maurício de Nassau em Recife, Pernambuco. Coordena o Grupo de Estudos de Direito Público da Faculdade Boa Viagem.

Thaís VANDRESEN

Doutoranda em Ciência Jurídica pela Universidade do Vale do Itajaí - UNIVALI. Mestre em Direito pela Universidade Federal de Santa Catarina - UFSC. Professora de Direito Constitucional e Direitos Humanos da Universidade do Vale do Itajaí - UNIVALI. E-mail: thais.sc@terra.com.br

\section{Resumo}

O presente estudo tem como objetivo analisar a possibilidade de institutos da democracia presentes no sistema doméstico e a sua potencial transição para a arena internacional. A ideia da democracia internacional é avaliada como potencial solução formal para a resolução do problema do déficit de participação da pessoa humana na esfera internacional. Nesse sentido, utiliza-se o método comparativo e três teorias representadas por DAHL, HELD e PETERS são propostas e analisadas em conjunto antes de se propor a sua composição final. Para tanto, inicia-se o trabalho com a descrição do Estado moderno e a sua transnacionalização, ficando a ideia de democracia adjacente a esta estrutura, acompanhando-a em sua trajetória evolutiva. Em seguida, passa-se a analise da potencial transnacionalização dos sistemas democráticos com o resultado de que apesar de possível e desejável o sistema ainda precisa evoluir para que isto seja empiricamente exequível. 


\section{Palavras-chave}

Estado Moderno; Democracia Internacional; Transnacionalização.

\section{Abstract}

The present paper has as its main goal to analyze the possibility of the transition of democratic institutes present in the domestic system towards the global arena. The idea of an international democracy is evaluated as a potential formal solution to the democratic deficit resulting in the low citizen participation in the global sphere. In this sense, using a comparative model, three theories represented by DAHL, HELD and PETERS are proposed and analyzed together before proposing a final composition. First, a description of the modern State and its transnationalization is proposed, where democracy is adjacent to this creation and development. Next, the potential of the transnationalization of democracy is studied, and its result is that even though it is seen as possible and desirable, the system still needs to evolve so that it can be attainable.

\section{Key words}

Modern State; Global Democracy; Transnationalization.

\section{Introdução}

O Estado moderno caminha de mãos dadas com a democracia liberal e o sistema legal constitucional. Uma modificação na sua estrutura interna (e em suas relaçóes de poder) implica, horizontalmente, uma mutação no seu sistema legal e político. Abraham Lincoln definia democracia como o governo do povo, pelo povo e para o povo, mas o contexto dentro do qual ele se inseria já não se encontra mais presente.

Observando a evoluçáo do Estado-nacional, nota-se que ela reflete diretamente na ação política do mesmo, ou seja, na forma de representação política e legitimação do poder estatal e nas instituiçóes jurídico-constitucionais que o sustentam. Esta transformação demanda novas formas de se compreender tanto a representação como o funcionamento legal do Estado, pois os antigos métodos de legitimação (formados de acordo com e destinados ao Estado-nação do século passado) aparentam obsolescência e ineficácia, conduzindo a uma crise de legitimidade que possivelmente é, em suma, a máscara de uma deficiência perceptiva, mas que entretanto, demanda a busca imperativa de novas bases de validação de poder, principalmente quando a ideia de esferas transnacionais politicas de poder entram no cenário em questão. Questionase o futuro da democracia em um contexto global, principalmente quanto a sua 
sobrevivência em uma relação de legitimação onde cidadão e governo aparentemente estão tão distantes.

Portanto, o presente estudo trata de uma atualização do conceito clássico de Democracia e de sua vinculação exclusiva ao Estado Nacional. A problemática central apresentada terá como objetivo transitar entre o conceito clássico de Estado e democracia e a visão atual desses dois em um cenário globalizado.

O referencial teórico utilizado transita entre três visóes políticas de democracia e sistemas internacionais. Na primeira, mais clássica, trata-se da visão descrita por DAHL, que vê a impossibilidade de uma nova ruptura que transcenda a democracia para um novo nível global. Logo a seguir trata-se da corrente defendida por HELD, que apesar de compreender processos democráticos internacionais como possíveis, exige para tanto a criação de uma nova forma de se entender democracia e Direito Internacional. Por último, a visão mais recente do fenômeno, que é central para a conclusão desse trabalho e fechamento da sua problemática, defendida por PETERS, que trata da relação entre processos domésticos e internacionais ao analisar a Democracia na esfera Global. Inicialmente trata-se da democracia e do Estado moderno e de seu trânsito internacional. Mais adiante discute-se a democracia global e as três correntes supra descritas.

\section{Democracia e o Estado Moderno}

O Estado moderno tornou-se, junto com a democracia representativa, o padrão de poder legítimo, já que a força é consentida pelo povo e dividida pelo governo. Os responsáveis pela política pública têm accountability eleitoral (ou input accountability) por estarem submetidos a um processo de seleçáo ligado aos cidadáos-eleitores e tem output accountability devido à possibilidade de terem suas açóes questionadas pelo povo (dentro de um território limitado) (HELD, D. 1991, p. 198).

A nação que possibilita essa esfera democrática, tem raiz semântica na natio romana, deusa que possibilita o nascimento (eis a semelhança nos vocábulos). Seu sentido clássico demonstra que um agrupamento humano denominado nação é aquele que tem vínculos além daqueles que o tornariam um gens ou populus. O sentido de nação traz em si um conceito de comunidade, formando entre os nacionais um demos (HABERMAS, 2003 (1929) v. 2 p. 282).

Esta mesma nação, ao organizar-se política e juridicamente, transforma-se no Estado moderno, que passa mais uma vez por uma crise de identidade. Mas antes de discutir esta crise, faz-se necessário visitar outros eventos que influenciaram sua construção/idealização. 
Desde o final da segunda guerra mundial o Estado-Nação tem sido o principal tipo de poder político através do globo. Com o processo de descolonização do pós-guerra e a queda do Império Soviético, o número de Estados-nacionais multiplicou-se de $81 \mathrm{em}$ 1950 para 167 em 1991 (Idem, p. 54). Também é de se notar que nesse mesmo período ocorreram a segunda onda democratizante reversa e a terceira onda.

A democracia trouxe dentro de si um ideal legitimador baseado na igualdade política, participação e inclusão dos governados, bem como responsividade e responsabilização dos atores governamentais através de mecanismos de sanção e desempoderamento. Contudo, a amplitude e consideração desses elementos podem fazer surgir várias ideias e concepçóes do que pode estar incluído dentro desse modelo teórico.

Portanto, procurando aproximar uma solução do que seria o ideal democrático, deve-se inicialmente definir quais os fatores que levaram um sistema a ser definido como uma aproximação desse ideal, a poliarquia, e em seguida mencionar as condiçóes que favorecem ou não esta aproximação. Nesse sentido, Dahl caracteriza como chave da democracia para um grande número de pessoas a capacidade de o governo ser continuamente responsivo às preferências de seus cidadãos considerando-os como "politicamente iguais", tendo todos esses oportunidades plenas para formular e expressar preferências individual ou coletivamente e de serem estas preferências igualmente consideradas na conduta daquele (Dahl, 1997, pp. 25-26).

Estas qualidades variam segundo dois referenciais através dos quais se poderá comparar regimes democráticos, que são: o grau de oposição ou amplitude da contestação e a proporção da população habilitada a participar ou o grau de inclusão. Considera-se então a democratização como formulada por estas duas dimensóes, uma de contestaçáo pública e outra de participação.

Outra visão do que seria democracia parte de Schumpeter que a conceitua como um simples método de seleção de líderes políticos, rejeitando a ideia de que a democracia incorporaria ideais políticos acerca da participação política dos cidadãos na escolha de seus líderes. Ao fazer isto, rejeita também parte do que foi colocado por Dahl, excluindo qualquer consideração da democracia como um fenômeno histórico, dizendo apenas que, historicamente a democracia moderna cresceu com o capitalismo e em conexão causal com ele, havendo uma conexão entre o sistema capitalista e o método democrático. (SCHUMPETER, 1975 (1942) p. 269)

Esta conexão com o sistema capitalista faz com que se tenha uma visão minimalista da democracia, colocando o significado da democracia como o sistema onde o povo tem a oportunidade de aceitar ou recusar as pessoas designadas para governar, como em um mercado, onde a vontade do povo é o produto e não o motor do processo político, já que o poder de decisão é adquirido através de uma luta competitiva pelos votos da população. 
O partido político não é um grupo de pessoas comprometidas com o bem comum, mas sim um grupo que tem uma gama de princípios definidos que são escolhidos pelos cidadãos através do voto.

Concluindo sua teoria sobre a democracia, Schumpeter enumera quatro condiçôes para que o método democrático tenha êxito dentro das grandes naçóes modernas e industriais. A primeira refere-se à qualidade do material humano que chega ao gabinete e ao parlamento, sendo que devem ser escolhidos dentre a população aqueles que estiverem preparados e disponíveis para a vocação política. A segunda trata do alcance da decisáo política que não deve estender-se muito, mas sujeitar essa distância à qualidade dos homens e da máquina política e ao padrão de opinião pública com que se irá trabalhar. A terceira condição diz respeito à necessidade de se ter à disposição uma burocracia bem treinada e forte o bastante para guiar e instruir os políticos que encabeçam os ministérios. Já a quarta condição trata do autocontrole democrático, sendo que os políticos devem resistir à tentação de embaraçar o governo, com oferta de maníacos e velhacos, e conquistarem o respeito de seus eleitores, fazendo-os entender que após a eleição a ação política é sua tarefa e não deles.

Esta visão democrática é de extrema relevância pois traz dentro de si um critério objetivo para que se possa separar o que é uma democracia daquilo que não seria. Os ideias que tratam de democracias de forma abstrata, dentro da concepçáo de um modelo teórico inatingível, apesar de apresentarem critérios qualitativos não conseguem quantificar democracia global, por exemplo. Hoje, por estudo realizado sobre o ano referência 2014, verifica-se que existe no mundo 125 democracias eleitoras em um cenário de 195 Estados. Isto significa que cerca de 63\% do mundo apresenta-se dentro desse sistema, sendo Fiji, Kosovo e Maldivas os últimos desse grupo a adotarem esse sistema em 2014 (FREEDOM HOUSE, 2015).

Esta visão minimalista do que seria democracia hoje fora superada pelas óticas liberal e comunitária desse mesmo conceito. Novamente, mudando o prisma de definição do que seria democracia, agora dentro de uma visão republicana, inicia-se a definiçãa da importância desse modelo através da legitimação da força do Estado. Justifica-se a existência da sanção jurídico-política através de seu surgimento com o cidadão. Em outros termos, a sociedade compóe-se não de portadores de direitos, mas de cidadáos ativos que participam do processo político através do qual surge o controle estatal. A força surge de um processo de autodeterminação dos cidadãos, sendo um poder gerado comunicativamente, institucionalizando a liberdade pública e justificando a existência do Estado. Nesta mesma concepção republicana, ao votar os eleitores expressam suas preferências e estabelecem ligaçóes com seus representantes, licenciando assim o acesso às posiçóes de poder que ocupam. Cria-se aí uma ligaçáo direta entre o input do voto e o output do poder (HABERMAS, 2004 (1997), pp. 281-283). 


\section{Figura 1 - Relação dos Eleitores e Instituições num Território Limitado}

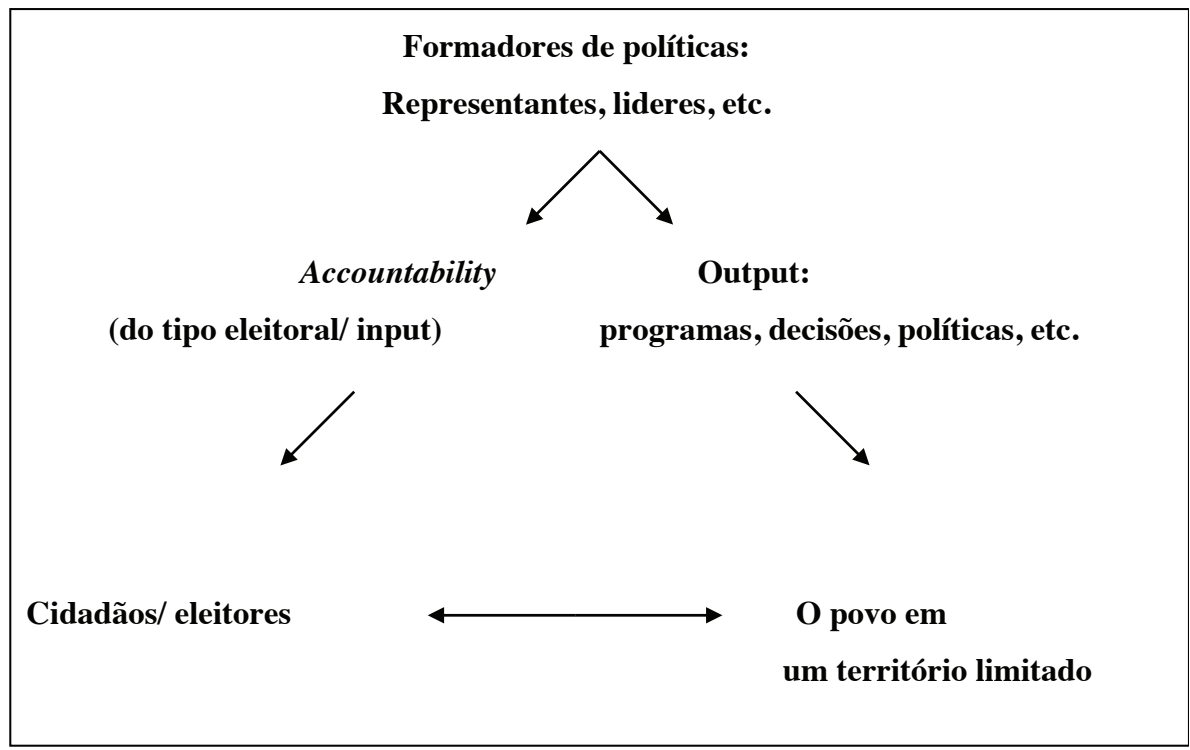

(Adaptado de HELD, D. 1991, p. 198)

Esta relação simétrica e congruente foi criada ao longo dos séculos XIX e XX e é aceita dentro do pressuposto da teoria democrática liberal. Segundo HELD (1999):

As premissas subjacentes da teoria da democracia, em resumo tanto em sua versão liberal como na radical-são as seguintes: que as democracias podem ser tratadas essencialmente como unidades auto-suficientes; que as democracias são claramente separadas umas das outras; que as mudanças no âmbito de uma democracia podem ser explicadas em grande parte por referência às estruturas internas e à dinâmica das sociedades democráticas nacionais; e que a política democrática expressa, em última análise, a interação de forças operando no plano do Estado-nação (HELD, 1999, p. 198).

Enquanto o processo de formação de uma vontade coletiva, nesta ótica republicana, mostra estar baseado em procedimentos de formação através do auto-entendimento ético, uma perspectiva deliberativa traz a institucionalização da deliberação, através da comunicação, que torna-se fator legitimador da formação da vontade e opinião pública.

O que se nota nestas correntes de pensamento é a necessidade constante de haver uma legitimidade do poder e da ordem pública. As variedades de pensamentos convergem para vários pontos e preocupaçóes comuns. 


\section{0 Trânsito Internacional}

Construída em uma concepção de Estado moderno, o desenvolvimento da democracia liberal como se nota hoje ocorreu em grande parte do globo em um pequeno espaço de tempo. Define-se esse Estado-Nacional moderno como o aparato político, com distinção entre governante e governado, com suprema jurisdição sobre uma dada área territorial, apoiado por uma posse do monopólio do poder coercitivo, baseado em uma relação tida como legítima. Os principais elementos desse conceito então são: a territorialidade, o monopólio do controle coercitivo, uma estrutura de poder despersonalizada e uma posse de poder legítimo.

Entretanto, o conceito parece estar sofrendo, junto com o sistema democrático que o que sustenta, nova faze de mutaçáo. Simultaneamente à mutaçáo do conceito de Estado e o surgimento de novas instâncias de poder público, surge também a deterioração da adesão popular as até então sólidas instituições representativas democráticas.

É possível detectar uma crise do sentimento de estar representado, que compromete os laços que idealmente deveriam ligar os eleitores a parlamentares, candidatos, partidos e, de forma mais genérica, aos poderes constitucionais. $\mathrm{O}$ fenômeno ocorre por toda parte, de maneira mais ou menos acentuada, atingindo novas e velhas democracias eleitorais (MIGUEL, 2003, p. 3).

Tendo em vista esse dado, seria ilógico considerar a situação até entâo descrita como predominante (democracia representativa e legitimidade do poder) como sendo idêntica à atual, já que existe na presente conjectura política influência de outras forças que nấo as estatais. A inter-conectividade global e regional que permeia as relaçóes domésticas hodiernas torna os destinatários de políticas nacionais não apenas aqueles limitados dentro do território limitado do Estado, deixando de ser apenas os nacionais os destinatários de tais políticas. Nas palavras de Held. "Once the 'relevant community' concept is tested in the global interconnectedness we reach the following questions: To whom decision makers have to justify their decisions? To whom should they be accountable?" (1995, p. 17). ${ }^{1}$

Esse fato torna necessária uma reavaliação da teoria democrática e por consequência uma reavaliação dos conceitos de legitimidade e de accountability dos Estados atuais, que claramente não são mais adequados aos processos de globalização (e de regionalização) presentes. Estariam esses Estados passando por mais uma onda reversa de democratização, camuflada de processo de mundialização?

1 Uma vez que o conceito de "comunidade relevante" é testado na rede global, chegamos as seguintes questôes: A quem os tomadores de decisóes devem justificar-se?A quem eles devem 'responsabilizar-se'? (tradução livre dos autores). 
Essa intrigante colocação torna necessário destacar o fato de que esses processos, a princípio econômicos, têm feito com os Estados cedam cada vez mais esferas de competências, antes exclusivamente suas, às organizaçóes e instituiçóes internacionais, tornando-se cada vez mais dependentes de regras e decisóes estranhas a sua política doméstica. O questionamento que logicamente decorre desta situação é se o poder, decisôes e açóes destas forças além do, ou superiores ao Estado Nacional, são ou não legítimas através do dito referencial teórico moderno do que seria democracia (em outras palavras, segundo a teoria democrática representativa).

Para Max Weber, um domínio legítimo, inclusive do poder Estatal, não é aquele que simplesmente está dotado de submissão exterior, ou desse caráter puramente normativo, mas aquele que desperta nos membros a fé em seu exercício, que transforma a sua disciplina em adesão à verdade que ele representa (FREUND, 2003, p. 166). Em suas palavras, existiriam três fundamentos de legitimidade: a tradicional, a legal-burocrática (racional) e a carismática:

Existem em princípio - e começaremos por aqui- três razões internas que justificam a dominaçáo, existindo, conseqüentemente, três fundamentos da legitimidade. Antes de tudo, a autoridade do 'passado eterno', isto é, dos costumes santificados pela validez imemorial e pelo hábito, enraizado nos homens, de respeitá-los. Tal é o 'poder tradicional', que o patriarca o senhor de terras, outrora, exercia. Existe, em segundo lugar, a autoridade que se funda em dons pessoais e extraordinários de um indivíduo (carisma) - devoção e confiança estritamente pessoais depositados em alguém que singulariza por qualidades prodigiosas, por heroísmo ou por outras qualidades exemplares que dele fazem o chefe. Tal é o poder 'carismático', exercido pelo profeta ou -no domínio político- pelo dirigente guerreiro eleito, pelo soberano escolhido através de plebiscito, pelo grande demagogo ou pelo dirigente de um partido político. Existe por fim a autoridade que se impóe através da razão da 'legalidade', em razão da crença na validez de um estatuto legal e de uma 'competência', positiva, fundada em regras racionalmente estabelecidas ou, em outros termos, a autoridade fundada na obediência, que reconhece obrigaçôes conformes o estatuto estabelecido (WEBER, M. 1999, p.57-58)

Importante notar a diferença existente entre uma autoridade que se impóe através da crença da validade de seus estatutos legais e comandos e de outra que se impóe através da força ou cuja obediência decorre de cálculos racionais de custo-benefício. Enquanto se seguem os comandos desta segunda ordem por prudência ou cálculo racional (devido ao poder que está implícito no mesmo), os comandos da primeira são moralmente vinculantes, sendo esse tipo de "motivação" para se seguir comandos, que Weber pretende ressaltar em sua colocação acima transcrita. 
Em Habermas encontra-se a necessidade da vinculação desse poder legítimo à figura do Estado de Direito, como se vê:

O estado é necessário como poder de organização, de sanção e de execução, porque os direitos têm que ser implantados, porque a comunidade de direito necessita de uma jurisdição organizada e de uma força para estabilizar a identidade, e porque a formação da vontade política cria programa que têm que ser implementados (HABERMAS, 2003 (1929), V. 1, p. 171).

Nesta mesma obra, mais adiante, cita Habermas a necessidade da participação do cidadão nesses processos internacionais, lançando o termo "arrogância do pós-nacional" quando tratando do passado e futuro do Estado Nacional.

Tratando do processo de unificação européia, diz o autor:

A dissolução das chaves semânticas que definem a cidadania e a identidade nacional corresponde ao fato de que a forma clássica do Estado nacional se encontra hoje em dissolução, à medida que a Comunidade Européia se transforma numa união política. Para entender isso, basta lançar um olhar sobre o modo como ela surgiu nos inícios da modernidade (HABERMAS, 2003 (1929), V. 2, p. 280).

Voltando a teoria de Dahl, a evolução da democracia limitada ao âmbito da cidade (direta) à democracia em contexto nacional (representativa) parece encontrar situação análoga a sua no presente contexto de expansão global supra mencionado. Como o Estado aparenta tornar-se insuficiente em determinados âmbitos de atuação, ocorre uma nova transformação democrática, partindo do Estado-nacional e evoluindo para o contexto transnacional. O próprio Dahl defende esta comparação de forma clara mais adiante em seu texto:

O resultado é como o processo da segunda transformação em escala mundial. Tanto como a ascensão do Estado-nacional reduziu a capacidade dos cidadãos locais exercerem controle sobre matérias de vital importância através de seus governos locais, a proliferaçáo de atividades e decisões transnacionais reduzem a capacidade dos cidadãos de um país exercerem controle de matérias de vital importância a eles através de seu governo nacional (idem, p. 3) ${ }^{2}$.

Outros autores, como Bob Jessop (in SANTOS, 2002), entendem existir três tendências gerais à transformação do poder do Estado: a desnacionalização, a de-estatização

2 Tradução livre dos autores, originalmente The result is something like the second transformation writ large on a world scale. Just as the rise of the national state reduced the capacity of local residents to exercise control over matters of vital importance to them by means of their local governments, so the proliferation of transnational activities and decisions reduces the capacity of the citizens of a country to exercise control over matters vitally important to them by means of their national government. 
dos regimes políticos e a internacionalização do Estado nacional. O primeiro movimento prega um esvaziamento do aparelho do Estado delegando seus poderes aos níveis subnacional e supranacional, enquanto o segundo reflete a mudança do papel estatal de governo centralizador para um governo de parcerias (de governaçáo ${ }^{3}$ ) e o terceiro, finalmente, insere o Estado nacional no contexto internacional de forma mais ativa, aumentando sua capacidade de ação e adequando as condiçóes internas às exigências estrangeiras. As três alternativas, entretanto, tem um ponto em comum: demandam mudanças institucionais e legais massivas (SANTOS in SANTOS, 2002, pp. 37-38).

(...) verifica-se o declínio do Estado-nação. Parece reduzir-se o significado da soberania nacional, já que o Estado-nação começa a ser obrigado a compartilhar ou aceitar decisóes e diretrizes provenientes de centros de poder regionais e mundiais. (...) Se por um lado o Estado-nação é levado a limitar e orientar os espaços da cidadania, por outro lado, as estruturas globais de poder são levadas a limitar e orientar os espaços da soberania nacional (IANNI, 1999, p. 16)

Por consequência, enquanto a capacidade de ação do Estado no âmbito internacional move-se cada vez mais em direção a ineficácia, aquilo que seria doméstico ou internacional se confundem. As relaçôes transnacionais e a globalização atravessam limites que fazem com que as próprias fronteiras que limitam o doméstico do internacional tornemse embaçadas (KEOANE, NYE. 2001, p. 3.).

A pressão sobre os Estados é agora relativamente monolítica - o "Consenso de Washington" - e em seus termos o modelo de desenvolvimento orientado para o mercado é o único modelo compatível com o novo regime global de acumulação, sendo, por isso, necessário impor, à escala mundial, políticas de ajustamento estrutural (SANTOS in SANTOS, 2002, p. 37).

O reflexo desta interdependência de Estados e a nova ordem global sobre o sistema clássico de representação e delegação de poder é devastadora. Na democracia representativa, aqueles que governam possuem clara relação de accountability com aqueles que são governados, podendo essas relaçóes serem das mais variadas possíveis. Da mesma forma, para que seja considerada legítima a atuação política além do estado nacional, esta deverá ter mecanismos apropriados de accountability, já que sem isto não haverá controle do poder. Entretanto, "estes mecanismos não podem simplesmente replicar, em escala maior, os procedimentos familiares e práticas dos Estados democráticos” (GRANT, KEOANE, 2005, p. 29).

3 O termo "governaçáa" vem de governance em inglês, que apesar de semelhante a governabilidade, significaria "o ato ou capacidade de governar". Esta tradução encontra maior divulgação no português ibérico que no americano, figurando inclusive na obra organizada por Boaventura Souza Santos supra citada (SANTOS in SANTOS, 2002) o esclarecimento da tradução no texto lido ao final da página 37. 
A criação de requisitos normativos institucionais para as operações do modelo de desenvolvimento neoliberal envolve, por isso, uma destruição institucional e normativa de tal modo massiva que afecta, muito para além do papel do Estado na economia, a legitimidade global do Estado para organizar a sociedade(SANTOS in SANTOS, 2002, p. 37).

A representação democrática direta não é a única forma de governação internacional contemporânea. A accountability pode ser criada às sombras das eleiçóes (KEOANE, NYE, 2001, p. 3).

Existirá accountability sempre que houver algum tipo de delegação de poder, criando um elo entre um mandatário e um agente. $\mathrm{O}$ fato de que havendo o descontentamento do mandatário para com o comportamento do agente implicará no seu afastamento é a essência da accountability. A relação de delegação corre em direção oposta a de accountability, indo a primeira do mandatário para o agente e a segunda do agente para o mandatário.

Accountability significa que o delegante tem o direito de retirar condicionalmente a autoridade delegada como um todo. Contudo, especialmente na política, raramente isto significa algo próximo de um afastamento imediato. Isto pode significar a recusa em renovar uma relação de delegação que tem um final previsto ou pode significar simplesmente a retirada da autoridade do agente, porém deixando-o em seu gabinete (SHUGART, MORENO e CRISP, 2000, p.4) ${ }^{4}$.

Nota-se que não existirá necessariamente uma relação eleitoral, mas sim uma relação de delegação de poder. Mas como falar em accountability sem antes tratar o problema da democracia em nível global? Pode-se dizer que três pensamentos destacam-se na ciência política contemporânea quanto a possibilidade da implementação da democracia em instituiçóes internacionais. O primeiro, encabeçado por Robert Dahls, nega tal possibilidade, enquanto o segundo, liderado por David Held ${ }^{6}$, define a atual governação internacional como não-democrática porém plausível de democratizar-se. O terceiro, defendido por Anne Peters como Dual Democracy (traduzido como democracia dúplice) trás um estudo mais moderno e atual de como seria possível implementar-se esse sistema democrático internacional.

4 Tradução livre dos autores, originalmente: Accountability means that the principal has the right to withdraw the conditionally delegated authority altogether. This usually means dismissing (firing) the agent. However, especially in politics, often it means something short of immediate dismissal. It may mean refusing to renew a delegation relationship that has a fixed endpoint or it may mean simply downgrading the agent's authority, but allowing the agent to retain her office.

5 Em especial na obra Can international organizations be democratic? A skeptic's point of view, in SHAPIRO e HACKER-CORDÓN, 1999.

6 Em especial na obra Models of Democracy, 1996. 


\section{A Democracia Internacional}

Como defensor da primeira visão, que nega a possibilidade de existir democracia além do Estado-nação, Robert Dahl alerta que deverá haver cautela quando da transferência de autoridades para essas instituiçōes. Antes de fundamentar o por quê de seu descrédito, Dahl situa a democracia sobre um tripé composto pela lei do povo (demos), um governo que seja responsivo e accountable e com uma autoridade soberana que decide sobre matérias políticas diretamente em assembleias ou indiretamente através de representantes (esses selecionados por sorteio ou eleiçôes). Também permite que haja uma visão da democracia como um corpo extensivo de direitos, porém descarta esse modelo, reconhecendo que a primeira visão é mais familiar. Ao dizer que irá utilizar um padrão que possibilite ver a democracia como um sistema de controle popular sobre políticas e decisões governamentais, adianta: não haverá governo em instituição internacional que se reconheça nesse modelo (DAHL in SHAPIRO e HACKER-CORDÓN, 1999, p. 20).

Suas conclusóes começam com o fato de que instituiçóes internacionais não são indesejadas, vindo até a facilitar a transição de governos não democráticos para democráticos. Entretanto, elas não serão nada mais do que sistemas de barganha burocráticos, devendo haver cuidado ao se ceder legitimidade a essas instituições, comparando-as às tiranias que porventura poderão ser responsivas aos governados. Entretanto, para fundamentar seu argumento principal, assenta-se no fato de que a premissa de que o declínio da capacidade de entidades nacionais e subnacionais de governarem-se é inevitável por que a globalização é inevitável, é falsa. Devem os Estado criarem mecanismos de avaliação para esses "sistemas de barganha burocráticos não-democráticas" (undemocratic bureacratic barbaining system). Esses sistemas são desejáveis; porém até que ponto, já que custam à democracia (Idem, pp. 33-34)?

Do outro lado do prisma encontra-se a teoria cosmopolita da democracia de David Held. Esta teoria não prega a diminuição do poder nacional frente à realidade globalizada, mas sim a complementação do poder nacional através de instituições que, coexistindo com àqueles atores nivelados com o Estado nacional, através de instituições democráticas que formariam suas raízes e desenvolver-se-iam a partir daquele, sobressaindo aos mesmos apenas em esferas limitadas de atividade, que prova que tal sobressalto é necessário. Assim a instituição internacional não é democrática mas poderá vir a ser. Importante é notar a seguinte passagem da dita obra:

Dois requisitos distintos surgem: primeiro, se os limites territoriais da accountability podem ser reestruturados para que aqueles temas que escapam o controle do Estado-nação - aspectos de administração financeira, questóes ambientais, elementos de segurança, novas formas de comunicação- podem ser trazidos sob melhor controle democrático; e segundo, se o papel e local de agencias funcionais e reguladoras globais e regionais 
podem ser repensados, para que estes possam providenciais um ponto focal mais claro e coerente quanto a relaçôes públicas (HELD, 1996, p. $\left.354^{7}\right)$.

A accountability é elemento necessário para a constituição de uma instituição democraticamente aceita e, portanto, legítima. Lembrando que a legitimidade implica na aceitação do ator submetido ao processo governamental, que aceita que o mesmo é propriamente autoritário.

Instituiçóes internacionais tem pouca chance de se beneficiarem da legitimidade simbólica, afetiva ou tradicional.Os seus defensores parecem justificá-las em termos de eficácia aparente: a função essencial que elas têm em promover cooperação internacional providenciando bens públicos globais. Tal justificação é importante, porém raramente suficiente na era democrática. No mundo atual existe uma demanda geral por accountability. Para que instituiçôes internacionais sejam legítimas, o desafio da accountability precisa ser confrontado ${ }^{8}$ (KEOANE, NYE. 2001, p.1).

Não havendo mais esta relação simétrica e congruente entre os atores responsáveis pelas decisões políticas e aqueles que são destinatários desta ação política, dois problemas surgem. O primeiro diz respeito ao input, ou seja, quem são os constituintes desses atores, enquanto o segundo diz respeito ao output, que materializa-se nas açóes de fato desses atores (HELD, 1996, p. 335).

Tanto como a representação, a accountability em nível global requer novas formas de análise, já que desde o início não se pode identificar de forma clara quem é o público, ou aqueles que estariam delegando poder. Concebem-se sete mecanismos de accountability alternativos, que não aquele derivado de uma relação eleitoral, para governos globais, são estes: accountability hierárquica, supervisora, fiscal, legal, de mercado, horizontal (ou de parceiros) e de reputação pública (GRANT, KEOANE. 2004, p. 33).

Dessas sete destaca-se a accountability legal, que refere-se a imposição dos detentores de poder limitarem-se a regras formais e estarem prontos para justificar suas açóes nesses

7 Traduçáo livre dos autores, originalmente: Two distinct requirements arise: first, that the territorial boundaries of systems of accountability be restructured so that those issues which escape the control of a nation-state - aspects of monetary management, environmental questions, elements of security, new forms of communication - can be brought under better democratic control; and, second, that the role and place of regional and global regulatory and functional agencies be rethought, so that they might provide a more coherent and useful focal point in public affairs.

8 Tradução livre dos autores, originalmente: International institutions have little prospect of benefiting from symbolic, affective or traditional legitimacy. Their defenders tend to justify them in terms of their apparent efficacy: the essential role they play in promoting international cooperation and providing global public goods. Such a justification is important, but rarely sufficient in a democratic era. In today's world, there is also a widespread demand for accountability For international institutions to be legitimate, the challenge of accountability must be confronted. 
termos frente a cortes e tribunais internacionais. Apesar de suas açóes serem discricionárias, essas estarão limitadas pelo escopo legal. A accountability legal é própria das democracias constitucionais, restringe-se ao estrito cumprimento da lei, porém é um forte mecanismo de controle governamental.

\section{A Democracia Dúplice de Anne Peters}

O déficit democrático presente no sistema internacional é o seu principal agente deslegitimador. Como consequência, os Estados são estimulados a descumprir a esfera normativa internacional. Como já discutiu-se anteriormente, não se pode transferir a estrutura democrática nacional um nível acima, portanto existe a necessidade de se diluir e redesenhar o ideal democrático, mas ao mesmo tempo ele náo poderá perder o seu significado inicial. Pode-se dizer, em relação a estrutura normativa, que existe uma ligação extremamente forte entre a validade da norma e o processo democrático que leva a sua produção. A erosão desse processo tal como ocorre na lex mercatória ocasiona seu enfraquecimento (SCHMALZ-BURNS, 2001, p. 556).

O constitucionalismo global requer mecanismos democráticos dúplices (PETERS, 2011). Isto significa que a estrutura democrática deve ocorrer dentro do Estado nação e no sistema internacional, em múltiplos níveis de governação. Portanto, segundo a autora, a produçáo normativa deve trazer dentro de si o conteúdo da vontade do povo tanto no sistema interior quanto no sistema acima do Estado.

De um lado, cidadãos devem continuar a ter sua vontade mediada pelos Estados que agem por eles no sistema internacional (visão Estadocêntrica). Na visão Estadocêntrica, Estados como agentes principais das instituiçóes internacionais devem ser reassegurados e a sua influência deve melhorar. Mas como a referencia ultima da democracia é a influencia da pessoa natural, a democracia apenas estará presente até o limite onde os Estados de fato representam seus cidadãos (PETERS, 2011, p. 264).

Dessa forma, discute-se como anteriormente mencionado em DAHL, a possibilidade da governação global ser democrática por transitividade. Nesse sentido, ainda deve existir a possibilidade de accountability internacional. Deve-se observar que ser um Estado democrático não é o suficiente para que se obtenha democracia internacional. Como indica PETES, mesmo se todos os países do mundo fossem democracias isto náo elevaria o conceito para o nível internacional. Deve-se introduzir a voz do indivíduo no cenário global, deve-se criar mecanismos de accountability internacional.

Em um caso não muito recente, no Estado Brasileiro ainda recém democrático, podemos analisar as açóes do então Presidente Fernando Henrique Cardoso, enquanto o mundo assistia o Brasil, frente ao Fundo Monetário Internacional. Neste caso em específico, 
nota-se que o referido Chefe do Executivo transferiu parte da sua agenda política, que não teve apoio imediato do Senado Federal, para as políticas do Fundo. Portanto, naquele momento o país vivenciou a perda de controle democrático principalmente devido a falta de um instituto de accountability internacional.

Vreeland (1999: 2) shows how, in his recent negotiations with the IMF, President Cardoso of Brazil managed to negotiate an IMF package involving a fiscal adjustment programme which will immediately hurt many segments of society, while at the same time it is supposed to promote investor confidence. Previously, President Cardoso had had trouble convincing his governing coalition of the need to reduce public expenditure. Only by introducing the IMF agreement and by tying his preferred policies to the Fund's prescriptions could he win the support of Congress. Of course Congress could have objected again, but any rejection of the Fund's conditions would have implied that Brazil could not live up to the IMF's prescriptions ${ }^{9}$ (WOLF, 1999, 343).

Assim sendo, a implementação da democracia em uma escala global requer maior participação política da pessoa natural em cenário internacional. PETERS sugere a análise de três modelos clássicos: a democracia deliberativa, participativa e contestatória. No primeiro caso entende-se o deliberar diferente do votar. Há possibilidade de se entender a existência de deliberação internacional, desde que não se insira os elementos votar e demos ao processo internacional, que seria inviável (DYBERG, 2002).

A falta de estrutura deliberativa, contudo, faz com que esse modelo não seja plenamente possível. Mais adiante, a ideia participativa apresenta a inclusão de diversas esferas que vão além da pessoa natural, incluindo a sociedade civil. Nesse sentido, a comunicação e a tecnologia da informação potencializam esta modalidade de inclusão democrática. Isso dependerá, contudo, da mudança da ideia do voto para a ideia da voz, bem como dos interesses locais para interesses mais abrangentes. Já no modelo contestatório, que apresenta-se mais apto a transferência para o contexto global, entende-se que a ideia de consentir não é tão relevante quanto o poder de contestar, de refutar as açóes dos agentes políticos. A ação política apenas existirá se sobreviver à contestação do povo. Deve-se, portanto, criar institutos e mecanismos para que esse tipo de ação seja possível em

9 Vreeland (1999: 2) mostra como, em suas recentes negociaçóes com o FMI, o Presidente Cardoso do Brasil conseguiu negociar um pacote do FMI envolvendo um programa de ajuste fiscal, que irá imediatamente ferir muitos segmentos da sociedade, enquanto que ao mesmo tempo, supostamente, deveria promover a confiança dos investidores. Anteriormente, o presidente Cardoso tinha tido dificuldades em convencer sua coalizáo de governo da necessidade de reduzir a despesa pública. Somente com a introduçáo do acordo com o FMI e amarrando suas políticas preferenciais com as prescriçóes do Fundo, que ele conseguiu ganhar o apoio do Congresso. É claro que o Congresso poderia ter-se oposto novamente, mas qualquer rejeição das condiçóes do Fundo teria implicado que o Brasil não poderia viver de acordo com as prescriçóes do FMI (tradução livre dos autores). 
âmbito extranacional. Contudo ainda há o alerta: "deliberação e contestação não é o que os sem-poder requerem. Conclui-se que deliberação, participação e contestação não são substitutos reais para a democracia formal” (PETERS, 2011, p. 270).

Analisando a Organização dos Estados Americanos (OEA), por exemplo, vê-se que apesar dos elementos iniciais de democracias nacionais estarem presentes e de a organização ter realizado diversas açóes para incluir a sociedade civil e as agências não governamentais, a distância, falta de recursos e as complexidades do sistema OEA são fatores que náo contribuem para esse segundo nível de estruturação democrática.

Nesse sentido, para que exista a ideia democrática além do Estado, deve-se ter o Estado democrático como porto de partida. Em contrapartida, a possibilidade de se responsabilizar organismos internacionais, de se contestar as açóes praticadas por eles deve ser meta estrutural do sistema.

Aproximando esse sistema daquilo que se estrutura de forma normativa dentro do direito, entende-se que o direito internacional está incorporando a necessidade do Estado produzir norma com legitimidade democrática. Lembrando o estudo mencionado pela FREEDOM HOUSE (2015), 63\% do mundo já se constitui sobre a forma de uma democracia eleitoral (visão Schumpeteriana). A Carta da ONU, proclamada pelos Povos das Naçôes Unidas, já apresentava em 1945 esse ideal. Contudo, PETERS indica que as oligarquias estatais, a ideia das aprovaçóes por unanimidades (e não maiorias), a falta de inclusão democrática na política internacional e a criação de organizaçóes internacionais tecnocráticas (e não democráticas como o FMI), contribuem para o contra argumento. Apenas com o empoderamento do cidadão e a formação de uma cidadania transnacional poderão esses fatores diminuírem, com um sistema democrático internacional criado com base na diversidade de identidades com diferenças solidárias. Para tanto, ainda se exige a participação da sociedade civil organizada (ONG’s) para que esse ideal de democracia dúplice se estabeleça.

As tensôes criadas entre as obrigaçóes internacionais e a democracia doméstica (como no caso do Brasil em 1999) são resultado desta relação dúplice existente entre o sistema internacional e o doméstico. $\mathrm{O}$ direito internacional e o direito nacional continuarão em situação de potencial atrito enquanto as tensões não puderem ser aliviadas por processos que aumentam a legitimação e controle do sistema normativo internacional tal como se faz em sistemas domésticos.

\section{Conclusões}

A democracia nacional e a falta dela no sistema internacional geram consequências graves na estrutura normativa do Direito. Esses sistemas plurais, em potencial conflito, buscam meios de legitimação e de reconstrução que possam aliviar as tensóes criadas entre si. Entende-se que o sistema está buscando alternativas materiais para esta resolução, 
como se encontra na criação de obrigaçóes erga omnes internacionais ou até na reorganização hermenêutica do sistema ${ }^{10}$. Contudo, a solução formal, que é a criação de estruturas democráticas legitimadoras ainda está longe de ser alcançada.

Tratou-se da análise da possibilidade da integração do sistema democrático com a esfera internacional. Nesse sentido aplicam-se três potenciais soluçóes, apresentadas respectivamente por DAHL, HELD e PETERS. A primeira traz consigo a ideia do fracasso inerente da estrutura democrática de transitar para o sistema internacional tal como está. Determinando que existe a necessidade de uma nova ruptura, DAHL deixa claro que no sistema atual não existe democracia internacional. HELD, por sua vez, incorpora a ideia do agir para democrático e da accountability democrática como instrumentos de trânsito que possibilitam não a transferência do sistema, mas de instrumentos que pertencem ao mesmo. Por sua vez, PETERS traz um estudo mais moderno e complexo, mas que a mesma ainda sugere poder ser um tigre de papel. $\mathrm{O}$ constitucionalismo global pode ser um instrumento hermenêutico, mas as ideias apresentadas pela mesma superam as expectativas criadas tanto por DALH quanto por HELD.

A criação de sistemas de accountability e a participação da sociedade civil internacional vêm transformando o ideal democrático em cenário global. Isto posto, encerra-se temporariamente esse estudo com a constatação de que o surgimento de novas democracias é uma realidade constante, contudo a proliferação desses institutos na plataforma normativa internacional, apesar de ser algo desejável, ainda é pouco provável dentro das estruturas hoje presentes.

\section{Referências}

Alter, K.; DEHOUSE, R.; VANBerg G.; Law, Political Science and EU Legal Studies: An Interdisciplinary Project? Londres, Thousand Oaks, New Delhi, Sage Publications: 2002, Volume 3 (1): 113-136.

ARATO, A. Representaçáo, soberania popular, e accountability. Lua Nova, 2002, no. 55-56, p.85-103.

ARJOMAND, S. A. Law, Political Reconstruction and Constitutional Politics. International Sociology. Londres, Thousand Oaks, New Delhi, Sage Publications: Março 2003, Vol 18(1): 7-32.

ARJOMAND, S. A. Constitutions and the Struggle for Political Order: A Study in the Modernization of Political Traditions', European Journal of Sociology, 1992, 33(4): 39-82.

10 Esse tema foi tratado em outra oportunidade em artigos diversos, e apresentado pelos autores, no II Encontro Internacional do CONPEDI (Baltimore), explicando a adoçáo do critério material do Direito e obrigaçóes Humanitárias como elemento estruturante desambiguador. 
AZOULAI, L. The Acquis of the European Union and International Organisations. European Law Journal, Vol. 11, No. 2, March 2005, pp. 196-231.

BEETHAM, D.; LORD, C. Legitimacy and the European Union. Londres e Nova Iorque: Longman,1998.

COGLIANESE, C. Transforming global governance: from Nation States to international institutions, 1999. Disponível em na data de 18/09/2009 em: [http://www. ksg.harvard.edu/prg/cary/global.pdf].

DAHL, R. Poliarquia: Participação e Oposição. São Paulo: Ed. Edusp, 1997.

DAHL, R. Democracy and its critics. Londres: Yale University Press, 1989.

DAHL, R. A democratic dilemma: system effectiveness versus citizen participation. Political Science Quarterly. V.109, n1,1994.

DYBERG, P. Accountability and Legitimacy, What is the Contribution of Transparency. In Arnull, A. e Wincott D.: Accountability and Legitimacy in the European Union: Studies in European law. New York, Oxford University Press: 2002.

FREEDOM HOUSE, Freedom in the World - Electoral democracies 2014. Acesso em 24.05.2015. Disponível em: [https:/freedomhouse.org/sites/default/files/ Number\%20and\%20Percentage\%20of\%20Electoral\%20Democracy\%2C\%20 FIW\%201989-2015.pdf]

HARLOW, C. Problems of accountability in the European Union. National Europe Centre Paper No 53. Disponível no dia 25/05/2005 em [http://www.anu.edu.eu/ NEC/harlow.pdf]

HELD, D. Models of Democracy. 2aed, Londres: Stanford University Press, 1996.

HELD, D. Democracy and the Global Order: From the Modern State to the Cosmopolitan Governance. Londres: Stanford University Press, 1995.

HELD, D. editor. Political Theory Today, Londres: Stanford University Press, 1991.

HELD, D, et. al. Global Transformations : politics, economics and culture. Londres : Stanford University Press, 1999.

JONGHE, K.; BURSENS, P. The quest for more legitimacy in the European Union as a Multi-Level Political System: a Conceptual Framework. In: ECPR Congress, Edingburg, 28 de março a 02 de abril de 2003.

KEOANE, R; NYE Jr, J. Democracy, Accountability and Global Governance. 2001. Disponível no dia 25/05/2005 em [http://www.ksg.harvard.edu/prg/nye/ggajune. pdf].

KEOANE, R; NYE Jr, J. The Club Model of Multilateral Cooperation and Problems of Democratic Legitimacy. 2000. Disponível no dia 25/05/2005 em [http://www. ksg.harvard.edu/prg/nye/clubmodel.pdf]. 
KOHLER-KOCH, B. Europe in Search of Legitimate Governance; Advanced Research on the Europeanisation of the Nation State. - ARENA, (Oslo) working paper 27/1999.

LIJPHART, A. Modelos de democracia. Rio de Janeiro: Civilização Brasileira, 2003.

IANNI, O. A era do globalismo. $4^{\mathrm{a}}$ ed. Rio de Janeiro, Editora Civilização Brasileira: 1999.

MAINSBRIDGE, J. (2003) Rethinking Representation. In American Political Science Review, vol 97, No. 4, nov. 2003.

MAGNOLI, D. Globalizaçáo, Estado Nacional e Espaço Mundial. São Paulo: Moderna, 1997.

PETERS, A. Dual Democracy. In KLABBERS, J., PETERS, A. e ULFSTEIN, G. Constitutionalization of international law. Oxford: Oxford University Press, 2011.

PITKIN, H. F. The Concept of Representation. Berkley: Univiersity of California press, 1972.

SANTOS, B.S. A Globalização e as Ciências Sociais. São Paulo: Cortez Editora, 2002.

SANTOS, M; et. al. (org.). O Novo Mapa do Mundo: Fim de Século e Globalizaçáo. São Paulo, Editora HUCITEC: 1997.

SHAPIRO, I.; HACKER-CORDÓN. Democracy's Edges. Cambridge University Press, 1999.

SHAPIRO, M; AlLTER, K J.; HELFER, L R. Do the Lessons of EU Legal Integration “Travel”? ECSA Review (13: 1), Winter 2000, pp. 2-6. Disponível no dia 27/06/2005 em [http://www.eustudies.org/win_2000.html].

SOARES FILHO, J. Elementos da Ordem Jurídica internacional e Comunitária. Editora Juruá: Curitiba, 2003.

STEFFEK, J. The legitimation of International Governance: A discourse Approach. European Journal of International Relations, Vol.9 (2), p. 249-275, 2003.

WEBER, M. Ciência e Política: duas vocaçóes. São Paulo: Cultrix, 1999.

WOLF. K. D. The New Raison d'État as a Problem for Democracy in the World Society. European Journal of International Relations, Vol.5 (3), p. 333-363, 1999. 